\title{
Understanding the effect of co-reactants on ketonization of carboxylic acids in the aqueous-phase pyrolysis oil of wood
}

\author{
Il-Ho Choi ${ }^{1} \cdot$ Hye-Jin Lee ${ }^{1,2} \cdot$ Kyung-Ran Hwang $^{1}$ (D)
}

Received: 4 March 2021 / Accepted: 23 September 2021 / Published online: 8 October 2021

(c) The Author(s) 2021

\begin{abstract}
Ketonization of carboxylic acids is one of the crucial reactions to produce sustainable bio-fuel and bio-chemicals from the pyrolysis oil of wood. Ketonization using different mixed solutions of carboxylic acids, furfural, and hydroxyacetone has been explored to understand the influence of co-feed reactants on the performance of ketonization of carboxylic acid over the selected CeZrOx catalyst. Furfural (7\% in water) inhibited the catalytic activity for ketonization of acetic acid (20\% solution) with reversible blocking of active sites, but for a mixed solution of hydroxyacetone $(7 \%)$ and acetic acid (20\%), both reactants influenced each other, resulting in very low conversions and slow and uncompleted recovery to $50 \%$ after removing hydroacetone from the mixture. For the mixed solution $(20 \%$ acetic acid $+7 \%$ furfural $+7 \%$ hydroxyacetone in water), hydroxyacetone was the most reactive compound on $\mathrm{CeZrOx}$ and the conversions of reactants reached below $10 \%$, due to the inhibition of co-existing carbonyl components. This work provides guidance for ketonization of carboxylic acids in the aqueous-phase pyrolysis oil.
\end{abstract}

\section{Introduction}

Currently, renewable bio-fuels are receiving extensive interest as drop-in fuels, especially as governments consider a carbon-neutral growth strategy for the mitigation of carbon dioxide emissions. Lignocellulosic biomass is one of the promising resources from which renewable transportation fuel and chemicals can be produced through thermochemical transformation such as gasification and pyrolysis technologies. In particular, a high yield of liquid product (bio-oil) can be obtained from fast pyrolysis

Kyung-Ran Hwang

hkran@kier.re.kr

1 Energy Resource Upcycling Research Laboratory, Korea Institute of Energy Research, Daejeon 34129, Republic of Korea

2 Department of Chemical and Biological Engineering, Korea University, Seoul 02841, Republic of Korea 
of wood (Westerhof et al. 2012; Park et al. 2019). It is well known that the crude bio-oil can be upgraded into bio-fuel via hydro-upgrading processes and a number of studies including research on catalysts, reaction mechanisms and reaction conditions have been conducted (Han et al. 2019; Yu et al. 2017). Since wood consists of cellulose, hemicellulose, and lignin, if it is pyrolyzed, various organic compounds derived from cellulose and hemicellulose will be present in the crude bio-oil as well as diverse phenolic compounds derived from lignin. Up to $40 \mathrm{wt} \%$ of the bio-oil can be quantified due to the limited analysis tools and the heterogeneity of the oil strongly depending on the type of wood and pyrolysis conditions (Lyu et al. 2015). Furthermore, the typical bio-oil contains a large amount of water (17-30 wt\%) with a high level of oxygen (36-52 wt\%) and low pH (Wang et al. 2013). In other words, many issues should be overcome to chemically transform crude bio-oil into bio-fuel via hydro-upgrading processes.

One of the issues raised during the hydro-upgrading processes is severe coke formation originating from the unstable and reactive low-molecule oxygenates in the bio-oil, making long-term operation difficult. In general, the typical crude bio-oil contains large amounts of these lightweight components including acids, aldehydes, ketones and ethers, having a carbonyl functional group, $\mathrm{C}=\mathrm{O}$ (Wang et al. 2013). Therefore, a hydro-stabilization step is adopted for easier operation of the subsequent hydro-deoxygenation step (Boscagli et al. 2015; Han et al. 2020). However, the lightweight oxygenates still contain lower carbon number than jet and diesel fuels even though they undergo the hydro-stabilization and hydro-deoxygenation reactions, owing to their low-carbon numbers. On this account, the crude bio-oil has been separated into an oily phase and an aqueous phase. Low-molecule compounds in the aqueous-phase bio-oil have been further fractionated and converted to larger carbon chains via $\mathrm{C}-\mathrm{C}$ bond formation reactions (oligomerization, hydroalkylation and aldol condensation reactions) in order to enhance the yield of useful liquid fuels from lignocellulosic biomass (Raguindin et al. 2020; Shao et al. 2020).

Aldol condensation reaction is a well-known $\mathrm{C}-\mathrm{C}$ bond formation reaction, and many studies have been carried out to produce liquid fuel intermediates using various model compounds such as furfural $\left(\mathrm{FF}, \mathrm{C}_{5} \mathrm{H}_{4} \mathrm{O}_{2}\right)$ and acetone $\left(\mathrm{C}_{3} \mathrm{H}_{6} \mathrm{O}\right)$ (Su et al. 2017; Dubnová et al. 2020). In this case, carboxylic acids $(\mathrm{RCOOH})$ should be removed or be limited from the reactants prior to the aldol condensation reaction, because of the stability of the basic catalysts such as $\mathrm{MgO}$ and hydrotalcites. Practically, acetic acid $\left(\mathrm{AA}, \mathrm{CH}_{3} \mathrm{COOH}\right)$ is the most abundant carbonyl compound in the aqueous-phase bio-oil. Here, ketonization $\left(\mathrm{R}_{1} \mathrm{COOH}+\mathrm{R}_{2} \mathrm{COOH} \rightarrow \mathrm{R}_{1} \mathrm{COR}_{2}+\mathrm{CO}_{2}+\mathrm{H}_{2} \mathrm{O}\right)$ is crucial to reduce carboxylic acids in the aqueous-phase bio-oil and to form larger carbon chains (ketones, $\mathrm{R}_{1} \mathrm{COR}_{2}$ ). The produced ketones can be used as intermediates in the production of longer carbon-chain oxygenates, finally being converted into fuel-range hydrocarbons. Many different catalysts and the reaction mechanisms of ketonization have been reported in previous studies (Boekaerts and Sels 2021). In summary, high lattice energy oxides such as $\mathrm{CeO}_{2}$ and $\mathrm{ZrO}_{2}$ are available for the ketonization reaction with relatively high catalytic activity and are often used in biomass conversion reactions (Kumar et al. 2018). However, ketonization has been mostly studied using simple model compounds such as AA, even though different carboxylic acids and diverse 
oxygenate compounds exist in the real aqueous-phase bio-oil. These carbonyl components including acids, aldehydes, ketones, and alcohols may interact with catalyst surfaces and/or with each other to undergo chemical transformation to diverse products under the reaction conditions for ketonization. The ketonization of a $16 \mathrm{vol} \%$ AA solution was conducted over $\mathrm{Fe}_{0.2} \mathrm{Ce}_{0.2} \mathrm{Al}_{0.6} \mathrm{O}_{\mathrm{x}}$ catalyst in the presence of different components such as hydroxyacetone (HA, $\left.\mathrm{C}_{3} \mathrm{H}_{6} \mathrm{O}_{2}\right), \mathrm{FF}$, eugenol, and guaiacol. (Jackson 2013). 10 vol\% HA and 2 vol\% FF had little impact on the ketone yield and phenolics at high concentrations (e.g., 5 vol\% guaiacol) inhibited the catalytic activity. However, there are some limitations to understand the inhibition effects of coexistence components on the ketonization reaction due to the high reaction temperatures (above $400{ }^{\circ} \mathrm{C}$ ), because HA already disappeared at $400{ }^{\circ} \mathrm{C}$ over mixed oxide catalysts (Mansur et al. 2013). Furthermore, it was difficult to reveal why phenolics and FF at high concentrations in the mixed solution reduced ketone yield without evaluation of carbon balance and analysis of spent catalysts after reactions. Catalytic upgrading of an aqueous pyroligneous acid derived from slow pyrolysis of woodchips was carried out to investigate the effect of $\mathrm{ZrO}_{2}$ content in $\mathrm{ZrO}_{2}-\mathrm{FeO}_{\mathrm{x}}$ catalyst on ketone yields (Mansur et al. 2013). The presence of metal impurities ( $\mathrm{K}$ and $\mathrm{Mg}$ ) in the feedstock reduced ketone yield, but the pre-treatment of the pyroligneous acid using a cation-exchange resin solved this problem. However, the respective effects of co-existence carbonyl compounds have hardly been discussed due to the complexity of the pyroligneous acid. Consequently, it is impossible to reveal all-chemical transformations occurring among oxygenates owing to the diversity and heterogeneity of bio-oil. As the first step, it is very important to understand the effects of co-existing compounds with carboxylic acids on the catalytic behavior during the ketonization reaction. Therefore, in the present work, experimental observations are provided to understand the influence of co-reactants on the performance of ketonization over the selected CeZrOx catalyst. Different mixed model solutions were prepared representative of the light fraction of the aqueous-phase bio-oil, and ketonization has been studied in the coupling of different carboxylic acids, FF, HA, and mixed solutions. The effects of various reaction conditions (FF or HA concentrations in a $20 \mathrm{wt} \% \mathrm{AA}$ solution and reaction temperatures) were investigated on the catalytic performance for the ketonization of AA. Coke analysis of the spent catalysts and a time-on-steam (TOS) testing were involved to understand the behavior of co-reactants during the ketonization reaction of AA over $\mathrm{CeZrOx}$ catalyst.

\section{Materials and methods}

\section{Catalyst preparation and characterization}

A powder type $\mathrm{CeZrOx}$ mixed oxide catalyst was prepared by the co-precipitation method. Aqueous solutions of $\mathrm{Ce}\left(\mathrm{NO}_{3}\right)_{3} \cdot 6 \mathrm{H}_{2} \mathrm{O}$ (Aldrich, 99\%) and $\mathrm{ZrO}\left(\mathrm{NO}_{3}\right)_{2} \cdot \mathrm{xH}_{2} \mathrm{O}$ (Aldrich, 99\%), as precursors, were mixed according to the molar ratio of cerium and zirconium (1:1). $\mathrm{NH}_{4} \mathrm{OH}$ solution (Aldrich, 28 30\%) was added to the mixed precursor solution to obtain the precipitate. The slurry was aged by mild stirring at room temperature for $24 \mathrm{~h}$, followed by filtration, washing with ethanol and 
distillated water, and drying at $110{ }^{\circ} \mathrm{C}$ overnight. The dried solid was calcined at $450{ }^{\circ} \mathrm{C}$ for $2 \mathrm{~h}$ in air. Prior to use, the powder-type catalyst was pressed to a disk and then crushed and sieved to 40-60 mesh particles.

An X-ray diffraction (XRD) analysis of metal oxides was carried out using a Rigaku Smartlab XRD system with $\mathrm{Cu} \mathrm{K} \alpha$ radiation. The textural properties of the prepared catalysts were determined using the Brunauer-Emmett-Teller (BET) technique using a BELSORP-mini II (MicrotracBEL Co. Ltd.). A thermogravimetric analysis (TGA) of the used catalysts was conducted using a TGA Q500 with air to provide information on coke deposited on the used catalysts. TGA data were divided into three regions: weight loss below $300{ }^{\circ} \mathrm{C}$ corresponding to the desorption of water and volatile components, weight loss between 300 and $500{ }^{\circ} \mathrm{C}$ corresponding to the thermal coke, and weight loss between 500 and $750{ }^{\circ} \mathrm{C}$ corresponding to catalytic coke (Rezaei et al. 2015). Note that thermal coke is mainly deposited on the exterior of the catalyst as a result of thermal polymerization of components in gas phase, and catalytic coke is formed on the active sites in the pores of catalyst through reactions including condensation of oxygenates, oligomerization, etc.

\section{Catalytic reaction and product analysis}

A schematic drawing of the experimental set-up for the catalytic reaction is presented in Fig. 1. The prepared reactant solution was fed to a quartz bulb-reactor using an HPLC pump (Eldex Laboratories). The amount of loaded reactant solution was reported using a data logger, connected to a balance (A\&D Company) during the experiments. The sieved catalysts were placed in the reactor (ID $=1 / 4 \mathrm{inch})$, and

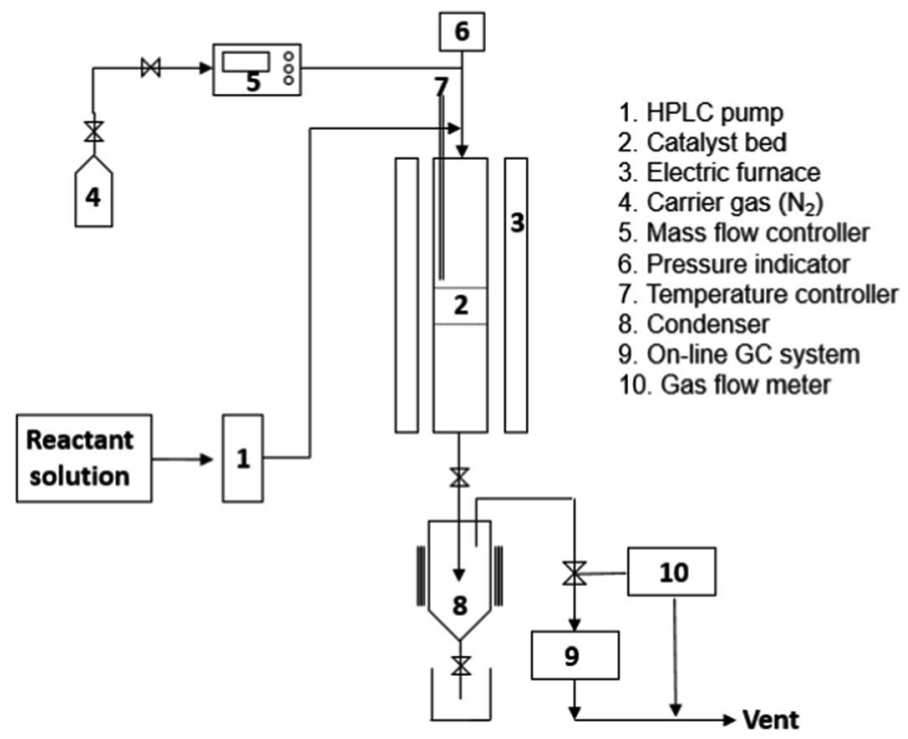

Fig. 1 Schematic drawing of the experimental set-up for catalytic reaction 
a K-type thermocouple was located in the reactor to control the reaction temperature. Nitrogen was used as a carrier gas $(15 \mathrm{ml} / \mathrm{min})$. To select the representative model reactants, the light fraction separated from the pyrolysis oil of saw-dust was analyzed using a gas chromatograph (GC, Agilent 7890A) equipped with a mass spectrometer (5975C). An HP-5 column $(30 \mathrm{~m} \times 0.32 \mathrm{~mm} \times 0.2 \mathrm{um})$ and a flame ionization detector (FID) were used, and the compounds were identified using the National Institute of Standards and Technology (NITS) Mass Spectral Library. For the ketonization reaction, a carboxylic acid solution (20 wt $\%$ in water) was prepared, and $7 \mathrm{wt} \%$ of FF and $7 \mathrm{wt} \%$ of HA were added to the carboxylic acid solution, unless specifically stated.

The collected liquid product from the condenser after the reaction was analyzed using a high-performance liquid chromatograph (HPLC, Shimadzu) with a refractive index detector and an Aminex HPC-87H column to determine the conversion of carboxylic acid and the product yield. A glycerol solution, $5 \mathrm{v} / \mathrm{v} \%$, was used as an internal standard, and $\mathrm{H}_{2} \mathrm{SO}_{4}$ solution $(0.005 \mathrm{~N})$ was used as a mobile phase for the HPLC analysis. The conversion of carboxylic acid and the yield of ketone product were calculated by the following equations.

$$
\begin{gathered}
\text { Conversion }(\%)=\left(1-\frac{\text { mole of unreacted carboxylic acid }}{\text { initial mole of carboxylic acid }}\right) \times 100 \\
\text { Ketone yield }(\%)=\left(\frac{\text { mole of produced ketone }}{\text { initial mole of carboxylic acid }}\right) \times 100
\end{gathered}
$$

The non-condensable gas was analyzed using an on-line gas chromatograph (GC, Agilent 7890A) equipped with a thermal conductivity detector (TCD) and FID. The columns were a Carboxen-1004 stainless steel column (Supelco, $2 \mathrm{~m} 1 / 16 \mathrm{in} . \times 0.75 \mathrm{~mm}$ ) for TCD and a GS-Alumina capillary column (Agilent J\&W, $50 \mathrm{~m} \times 0.53 \mathrm{~mm}$ ) for FID, respectively.

\section{Results and discussion}

\section{Model compounds of the fractionated aqueous-phase bio-oil and catalyst characteristics}

Although the composition of bio-oil is dependent on the type of wood as feedstock and the conditions of pyrolysis, the typical bio-oil contains a large amount of water and a vast variety of oxygenates and can be divided into two phases, oiland aqueous-phase oil (Wang et al. 2013). Crude pyrolysis oil of pine saw-dust was obtained from a bench-scale fast-pyrolyzer installed in the institute in order to analyze the composition of oil. The aqueous-phase bio-oil separated from the asreceived crude bio-oil was fractionated to obtain low-molecule carbonyl compounds at $180{ }^{\circ} \mathrm{C}$. Table 1 presents a summary of oxygenates in the fractionated aqueousphase oil, analyzed using GC/MS. Large amounts of acids, ketones, and aldehydes 
Table 1 Summary of lowmolecule carbonyl components in the fractionated aqueousphase oil at $180{ }^{\circ} \mathrm{C}$

\begin{tabular}{llc}
\hline Group & Oxygenates & GC peak area (\%) \\
\hline Acid & Acetic acid & 23.55 \\
& Propionic acid & 2.48 \\
& Butyric acid & 3.08 \\
Alcohol & 2-butanol & 1.02 \\
& 2-methyl-1-propanol & 1.20 \\
Aldehyde & Furfural & 10.94 \\
& Furfural, 5-methyl- & 1.28 \\
Ketone & 2,3-butanedione & 2.34 \\
& 2-propanone, 1-hydroxy- & 28.35 \\
& 2-cyclopenten-1-one & 1.94 \\
& 1-hydroxy-2-butanone & 2.18 \\
Phenol & Phenol & 3.09 \\
& Phenol, 2-methoxy-4-methyl- & 6.96 \\
& Phenol, 2-methoxy- & 9.65 \\
& Phenol, 4-ethyl-2-methoxy- & 1.92 \\
\hline
\end{tabular}

are included in the light fraction oil. The water content and $\mathrm{pH}$ of the fractionated oil were $45 \%$ and 2.9 , respectively. Therefore, different mixed model solutions representative of the light fraction in bio-oil were prepared, and ketonization was studied in the coupling of different carboxylic acids (AA and propionic and butyric acids), FF as aldehyde, HA as ketone, and the mixed solutions.

The XRD patterns of the prepared catalyst (CeZrOx) including individual metal oxides $\left(\mathrm{ZrO}_{2}\right.$ and $\left.\mathrm{CeO}_{2}\right)$ for comparison purpose are shown in Fig. 2. Characteristic peaks $\left(28.5^{\circ}, 33.1^{\circ}\right.$, and $\left.47.5^{\circ}\right)$ of $\mathrm{CeO}_{2}$ were presented in pure and mixed oxide catalysts (Hwang et al. 2011), and the tetragonal phase of $\mathrm{ZrO}_{2}\left(30.2^{\circ}, 35.2^{\circ}\right.$ and $50.6^{\circ}$ ) was observed in pure and mixed oxide catalysts (Basahel et al. 2015). However, an

Fig. 2 XRD patterns of the prepared catalysts $(\mathrm{ZrO} 2, \mathrm{CeZrOx}$, and $\mathrm{CeO} 2$ )

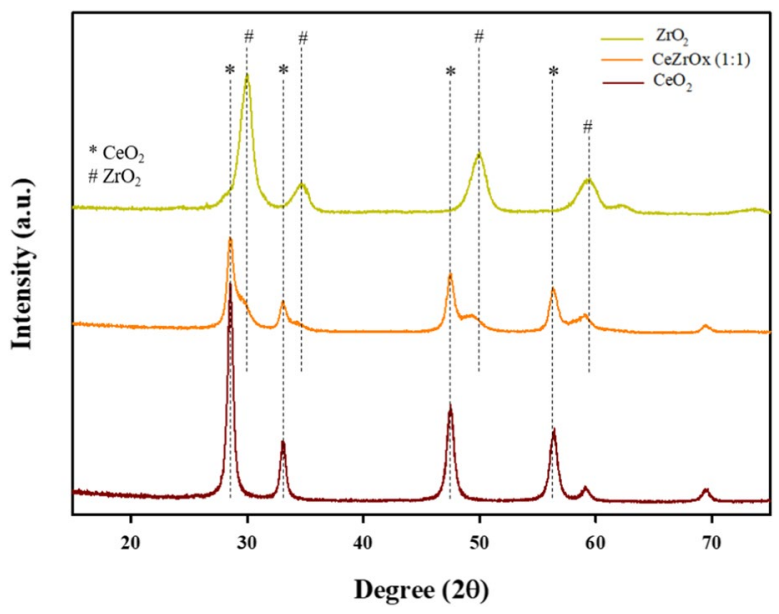


asymmetric (111) $\mathrm{CeO}_{2}$ diffraction peak $\left(2 \theta=28.5^{\circ}\right)$ and shift of the $\mathrm{ZrO}_{2}$ diffraction peak to lower 2 theta values were observed in the $\mathrm{CeZrOx}$ catalyst, indicating that cations of different sizes were partially incorporated in the structure of each oxide. The BET surface area and pore volume of the prepared catalyst are $72.9 \mathrm{~m}^{2} / \mathrm{g}$ and $0.154 \mathrm{~cm}^{3} / \mathrm{g}$, respectively.

\section{Ketonization of carboxylic acids}

Basically, ketonization of AA, a simple and abundant carboxylic acid in aqueous-phase oil, has been conducted over the CeZrOx catalyst, presented in Fig. 3. AA was converted completely into acetone over the $\mathrm{CeZrOx}$ catalyst $\left(2 \mathrm{CH}_{3} \mathrm{COOH} \rightarrow \mathrm{CH}_{3} \mathrm{COCH}_{3}+\mathrm{CO}_{2}+\mathrm{H}_{2} \mathrm{O}\right)$ and acetone yield (46\%) nearly reached the theoretical value $(50 \%)$ at above $350{ }^{\circ} \mathrm{C}$. Note that some acetone loss should be considered during sampling from the condenser due to its high volatility, despite complete conversion of AA. During the ketonization reaction at above $400{ }^{\circ} \mathrm{C}$, a trace amount of methane was observed in the gas products, owing to decarboxylation of AA over the CeZrOx catalyst $\left(\mathrm{CH}_{3} \mathrm{COOH} \rightarrow \mathrm{CH}_{4}+\mathrm{CO}_{2}\right)$ (Fig. 3b) (Lemonidou et al. 2013).

Figure 4 shows the results of ketonization of different carboxylic acid solutions on the $\mathrm{CeZrOx}$ catalyst. It has been reported the ketonization progresses through a surface carboxylate mechanism on $\mathrm{Ce}-\mathrm{Zr}$ mixed oxides, where the formation of the $\beta$-ketoacid intermediate between enolate and acylium intermediates is the key step (Kumar et al. 2018). The formation of $\beta$-ketoacid does not appear to be directly related to the chain-length of carboxylic acids (for normal, not branched, carboxylic acids), because the reaction starts from the adsorption of the carbonyl group in acids on the active site of the catalyst, followed by dehydrogenation of $\alpha$-hydrogen forming enolate, as described in Fig. S1 in Electronic Supplementary Material. However, relatively higher reaction temperatures are required for the ketonization reaction to proceed with an increase in the number of carbons in the molecules of carboxylic acids. The required temperature for the complete conversion of carboxylic acids followed the order: butyric acid $\left(450{ }^{\circ} \mathrm{C}\right)>$ propionic acid $\left(375^{\circ} \mathrm{C}\right)>\mathrm{AA}\left(350^{\circ} \mathrm{C}\right)$. Through the initial rate studies, the measured apparent activation energy was $98.5 \mathrm{~kJ} / \mathrm{mol}$ for the ketonization of AA in the solution (20 wt\% in water) over CeZrOx catalyst, which is in line with the previously reported value $\left(117.6 \mathrm{~kJ} / \mathrm{mol}\right.$ for $\mathrm{ZrO}_{2}$ ) (Ignatchenko and Kozliak 2012). Given that the activation energy value in the previous study, however, was determined from the ketonization of pure AA without any interference of water molecule, the measured value in the present study was relatively very low. This is likely due to the low-temperature $\left(450{ }^{\circ} \mathrm{C}\right)$ calcined $\mathrm{CeZrOx}$ catalyst, based on the results that Snell and Shanks (2013) reported for the ketonization of AA on two different $\mathrm{CeO}_{2}$ catalysts; $450{ }^{\circ} \mathrm{C}$ calcined $\mathrm{CeO}_{2}$ showed a lower activation energy $(78 \mathrm{~kJ} / \mathrm{mol})$ than $900{ }^{\circ} \mathrm{C}$ calcined $\mathrm{CeO}_{2}(161 \mathrm{~kJ} / \mathrm{mol})$, resulting from the differences in the crystallinity of the catalyst and internal mass transfer limitations on the catalyst. The apparent activation energies increased with the increase in the carbon number in carboxylic acids $(127.4 \mathrm{~kJ} / \mathrm{mol}$ for propionic 

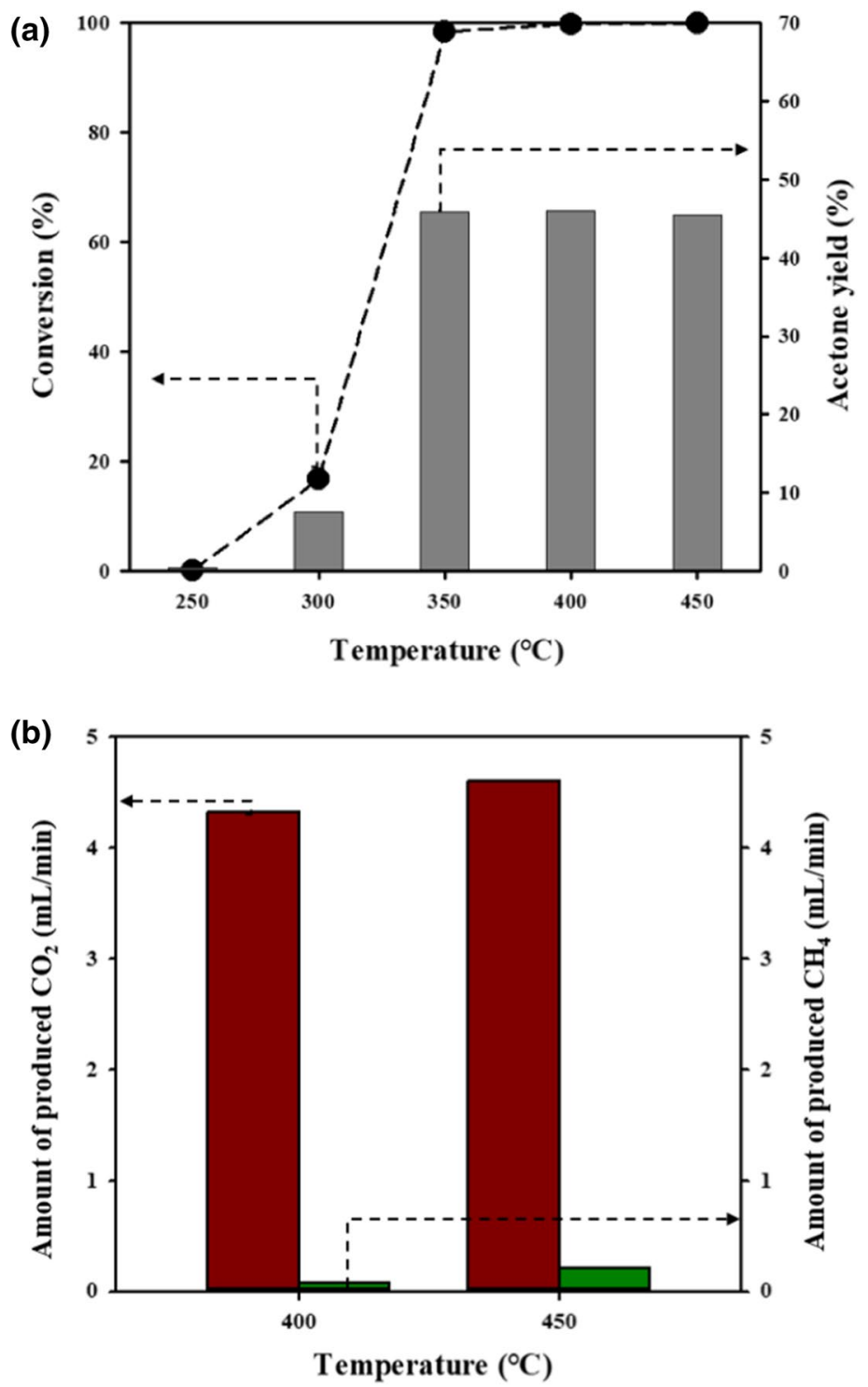

Fig. 3 Results of ketonization of AA solution ( $20 \%$ in water) over the CeZrOx catalyst at WHSV $=3 \mathrm{~h}^{-1}$ : $\mathbf{a}$ conversion of AA and acetone yield and $\mathbf{b}$ the amount of gas products

acid and $137.3 \mathrm{~kJ} / \mathrm{mol}$ for butyric acid, respectively), due to the steric effect of acids (Kulik et al. 2020). As shown in Fig. S2 in Electronic Supplementary Material, the difference in the conversions between pure AA and AA solution reactants indicates that the water molecules competitively adsorbed on the active sites on 
(a)

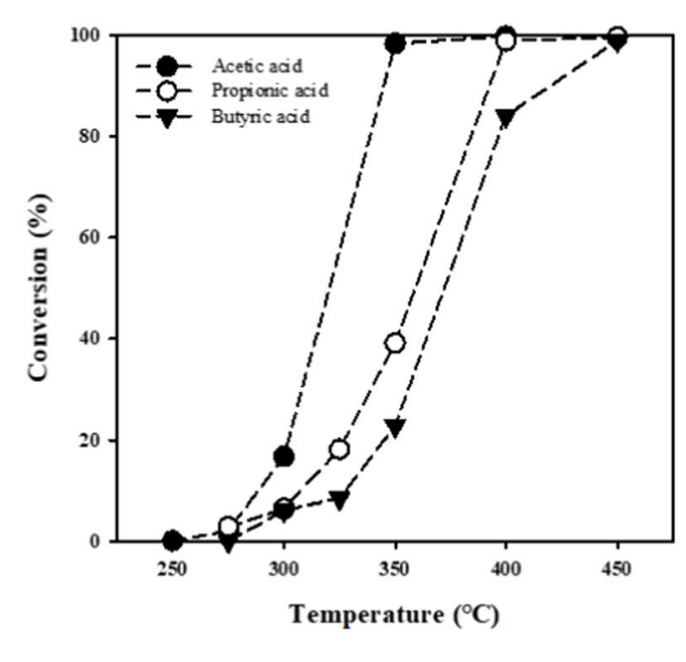

(b)

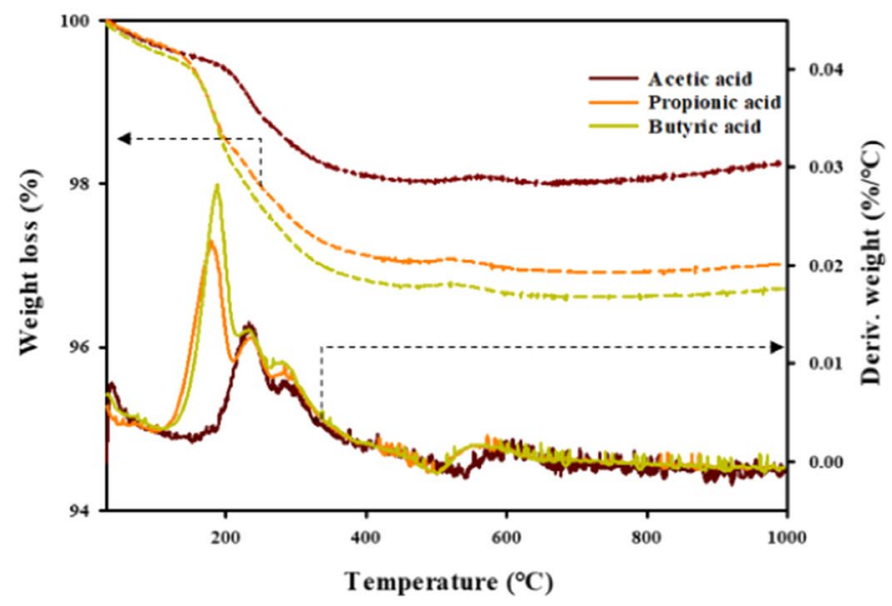

Fig. 4 Results of ketonization of different carboxylic acids (20\% in water) on CeZrOx catalyst at WHSV $=3 \mathrm{~h}^{-1}:$ a conversion of carboxylic acids and $\mathbf{b}$ TGA profiles of used catalysts

CeZrOx hinder the adsorption of AA molecules (Pham et al. 2012), resulting in the low catalytic activity.

After the reactions, a TGA analysis of the catalyst was carried out to examine coke formed over the surface of the catalyst, as shown in Fig. 4b. The catalysts after reactions using propionic acid and butyric acid had three significant weight loss peaks at around $100 \sim 300{ }^{\circ} \mathrm{C}$, unlike AA. Since weight loss at below $300{ }^{\circ} \mathrm{C}$ corresponds to the desorption of water and volatile components, the large weight loss peaks are likely due to unconverted acids, having higher molecular weight than AA, adsorbed on the surface of the catalyst. Table 2 summarizes the contents of thermal coke, catalytic coke, and total coke deposited on the used catalysts. The weight loss region below $300{ }^{\circ} \mathrm{C}$ is excluded in the calculation of thermal and catalytic 
Table 2 Comparison of coke deposited on the $\mathrm{CeZrOx}$ catalyst after a $250{ }^{\circ} \mathrm{C}$ to $450{ }^{\circ} \mathrm{C}$ reaction testing using different carboxylic acid solutions at $\mathrm{WHSV}=3 \mathrm{~h}^{-1}$

\begin{tabular}{llll}
\hline$\% \mathrm{~g}_{\text {coke }} / \mathrm{g}_{\text {catalyst }}$ & AA solution & $\begin{array}{l}\text { Propionic acid } \\
\text { solution }\end{array}$ & $\begin{array}{l}\text { Butyric } \\
\text { acid solu- } \\
\text { tion }\end{array}$ \\
\hline Thermal coke & 0.41 & 0.46 & 0.47 \\
Catalytic coke & 0.02 & 0.14 & 0.14 \\
Total coke & 0.43 & 0.60 & 0.61 \\
\hline
\end{tabular}

coke contents. There is no significant difference in the thermal coke contents, but a significant amount of catalytic coke was observed in the case of ketonization of propionic and butyric acids. Coke might be produced as a result of secondary and tertiary self-/cross-aldol condensation of formed ketones and further oligomerization on the active sites in the pores at relatively high temperatures. The longer the carbon-chain in the molecule of the reactant, the greater the potential for the formation of high molecule compounds through the consecutive aldol condensation-type surface reactions. $\mathrm{CeZrOx}$ has catalytic activity for aldol condensation and because of that various long-chain adducts originated from $\mathrm{C}_{3}$ and $\mathrm{C}_{4}$ acids-derived ketones might result in coke deposition on the active sites in the pores of catalyst. Because the same amount $(20 \mathrm{wt} \%)$ of acids was added in the water for each reactant solution ( $2.8 \mathrm{mmol} / \mathrm{ml}$ of propionic acid and $2.4 \mathrm{mmol} / \mathrm{ml}$ of butyric acid, respectively), a comparable amount of coke appeared to be formed for $\mathrm{C} 3$ and $\mathrm{C} 4$ acid solutions. For all reactants, the amount of thermal coke originated from the thermal polymerization of components in gas phase was obviously more than that of catalytic coke.

\section{Co-feeding reactants effect on the catalytic performance}

Reactions of FF or HA over CeZrOx have been observed under the reaction conditions of ketonization, prior to studying the effect of co-feeding reactants on ketonization of carboxylic acid. The results of FF (a) and HA (b) are shown in Fig. 5. When the FF solution ( $7 \mathrm{wt} \%$ ) was fed into the CeZrOx catalyst bed, the conversion of FF increased with an increase in reaction temperature and reached $100 \%$ conversion at $450{ }^{\circ} \mathrm{C}$ (Fig. 5a). However, significant products were not detected in the liquid product. Instead, a large amount of thermal coke was observed on the wall of the reactor and on the catalyst bed, which is more significant than HA. Some light components $\left(<\mathrm{C}_{5}\right)$ were detected in the gas products and the number and the intensity of gas components increased with the reaction temperature. (Unfortunately this could not be analyzed quantitatively.) Moreover, small amounts of $\mathrm{H}_{2}, \mathrm{CO}$, and $\mathrm{CO}_{2}$ were present from the reaction temperature of $400{ }^{\circ} \mathrm{C}$, likely due to partial steam reforming of $\mathrm{FF}$ on the $\mathrm{CeZrOx}$ catalyst. The produced hydrogen was about $7.6 \%$ of the hydrogen generated theoretically from global steam reforming of $\mathrm{FF}$ at $100 \%$ conversion $\left(\mathrm{C}_{5} \mathrm{H}_{4} \mathrm{O}_{2}+8 \mathrm{H}_{2} \mathrm{O} \leftrightarrow 5 \mathrm{CO}_{2}+10 \mathrm{H}_{2}\right)$. FF is one of the important molecules when considering $\mathrm{C}-\mathrm{C}$ coupling reactions for the fuel precursor owing to the higher carbon number of the molecule. However, most of FF appears to disappear into thermal coke at a relative low reaction temperature and into various gas-phase products above 400 on the CeZrOx catalyst. 


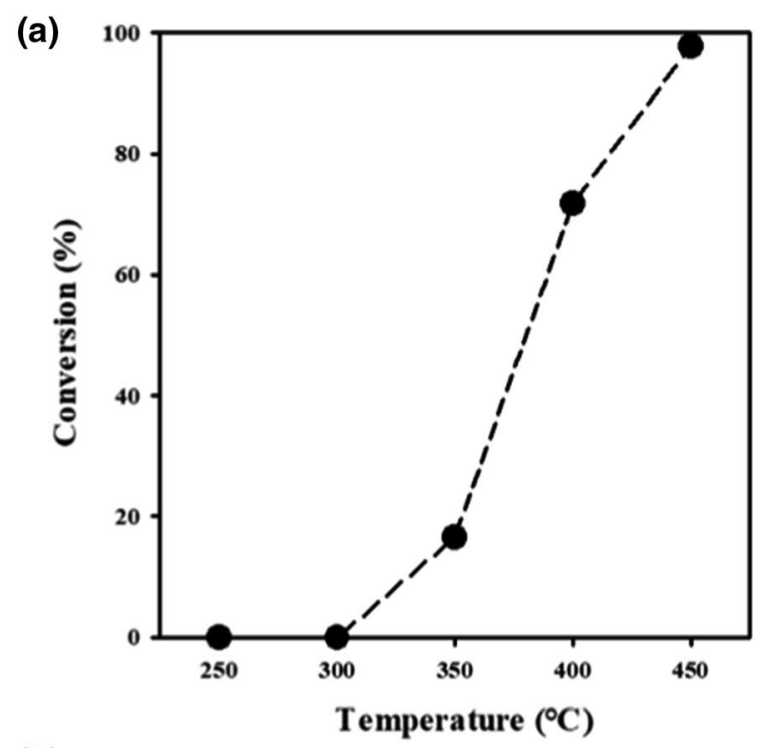

(b)

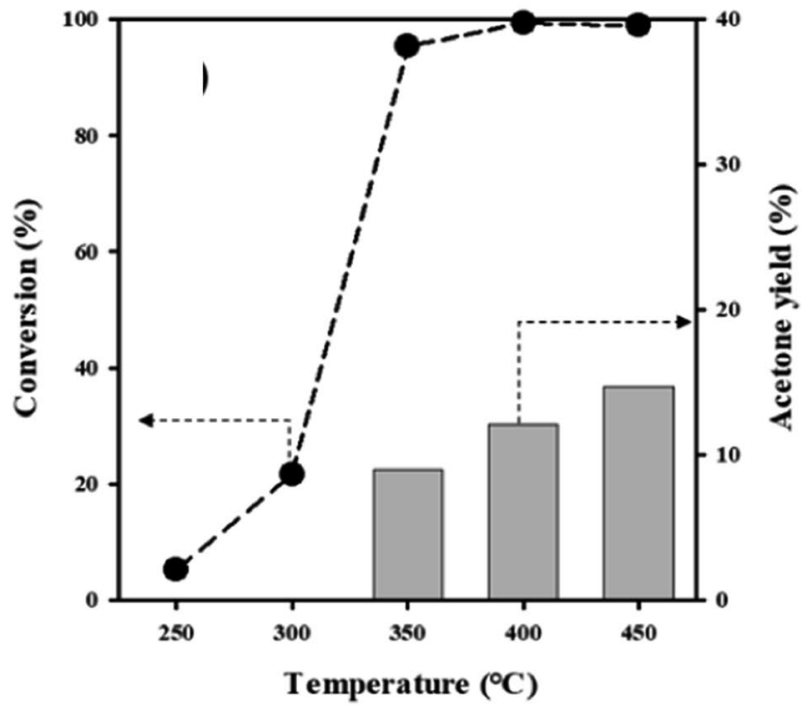

Fig. 5 Results of reactions of FF (7\% in water) and HA (7\% in water) over CeZrOx at WHSV $=1 \mathrm{~h}^{-1}$ : a conversion of $\mathrm{FF}$ and $\mathbf{b}$ conversion of $\mathrm{HA}$ and acetone yield

In the case of HA (Fig. 5b), the conversion was similar to that of AA, but the yield of acetone was very low, $15 \%$ at $450{ }^{\circ} \mathrm{C}$. Various different carbonyl compounds in the liquid products were observed, and we tried to analyze qualitatively some of them using HPLC-MS (shown in Fig. 6): acetone, propanal $\left(\mathrm{C}_{3} \mathrm{H}_{6} \mathrm{O}\right)$, 3-methyl2-cyclopentenone $\left(\mathrm{CH}_{3} \mathrm{C}_{5} \mathrm{H}_{5} \mathrm{O}\right)$, 2,5-hexanedione $\left(\mathrm{C}_{6} \mathrm{H}_{10} \mathrm{O}_{2}\right)$, AA, etc. Hakim et al. (2013) proposed that pyruvaldehyde $\left(\mathrm{C}_{3} \mathrm{H}_{4} \mathrm{O}_{2}\right)$ and 1,2-propylene glycol $\left(\mathrm{C}_{3} \mathrm{H}_{8} \mathrm{O}_{2}\right)$, 


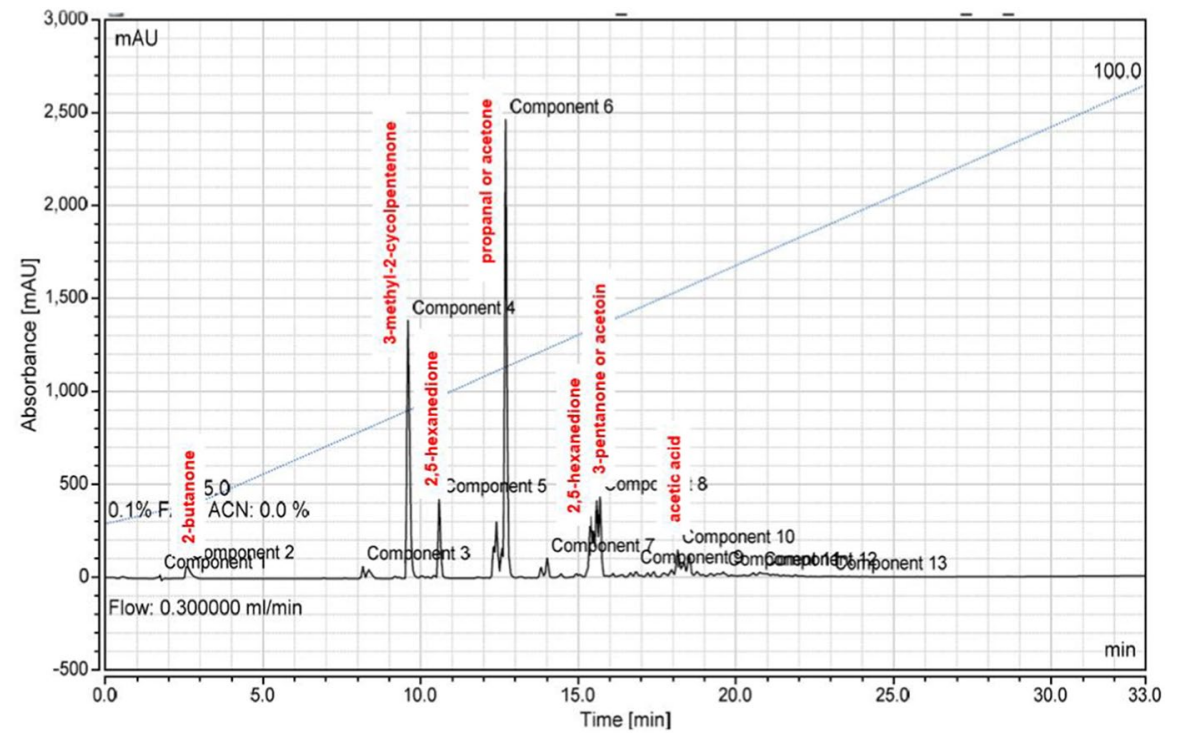

Fig. 6 Possible components in the liquid product obtained from HA solution ( $7 \mathrm{wt} \%$ ) under the ketonization reaction condition $\left(350^{\circ} \mathrm{C}, \mathrm{CeZrOx}\right)$

as important reaction intermediates, are formed from the hydrogen transfer reaction between two HA molecules. Based on their results, propanal and acetone can be produced from dehydration of 1,2-propylene glycol and AA formed from pyruvaldehyde can produce 3-methyl-2-cyclopentenone and 2,5-hexanedione via the aldol condensation reaction. As a result, $\mathrm{HA}$ was highly reactive on the $\mathrm{CeZrOx}$ catalyst and produced these various carbonyl compounds with less oxygen and below carbon number of 6 in their molecules. The physical appearance of the used catalyst bed and the reactor indicates that the amount of thermal coke appears to be much lower than when feeding FF. Small amounts of $\mathrm{H}_{2}, \mathrm{CO}$, and $\mathrm{CO}_{2}$ were detected from $400{ }^{\circ} \mathrm{C}$, likely due to partial steam reforming of $\mathrm{HA}\left(\mathrm{CH}_{3} \mathrm{COCH}_{2} \mathrm{OH}+4 \mathrm{H}_{2} \mathrm{O} \rightarrow 3 \mathrm{CO}_{2}+7 \mathrm{H}_{2}\right)$ on the $\mathrm{CeZrOx}$ catalyst, similar to FF. However, the amount of gases was half of the amount of gases from the steam reforming of FF. Table 3 summarizes the contents of thermal coke, catalytic coke and total coke deposited on the used catalysts, when feeding FF or HA under the reaction conditions for the ketonization reaction. As observed, FF formed much more thermal coke than HA. Although the amount

Table 3 Comparison of coke deposited on the $\mathrm{CeZrOx}$ catalyst after a $250{ }^{\circ} \mathrm{C}$ to $450{ }^{\circ} \mathrm{C}$ reaction testing using different reactants at $\mathrm{WHSV}=1 \mathrm{~h}-1$

\begin{tabular}{lll}
\hline$\% \mathrm{~g}_{\text {coke }} / \mathrm{g}_{\text {catalyst }}$ & $7 \mathrm{wt} \% \mathrm{FF}$ in water & $\begin{array}{l}7 \mathrm{wt} \% \\
\mathrm{HA} \text { in } \\
\text { water }\end{array}$ \\
\hline Thermal coke & 1.31 & 0.43 \\
Catalytic coke & 0.05 & 0.07 \\
Total coke & 1.36 & 0.50 \\
\hline
\end{tabular}


of catalytic coke was much lower than the amount of thermal coke in the present conditions, if FF and HA interact with the phenolic components present in the real pyrolysis oil at a relatively high temperature of around $300 \sim 400{ }^{\circ} \mathrm{C}$, a large amount of catalytic coke can be deposited on the surface of the catalyst (Xiong et al. 2020). Furthermore, the contents of thermal and catalytic cokes of FF and HA were much higher than those of AA, considering the WHSV of FF or HA was three times lower than that of AA.

Ketonization using two mixtures (AA and FF or AA and HA) has been conducted over $\mathrm{CeZrOx}$ at $350{ }^{\circ} \mathrm{C}$ in the fixed bed reactor. The effects of FF or HA concentrations on the ketonization of AA in the mixture were examined (Fig. S3 in Electronic Supplementary Material). As expected, FF and HA reduced the catalytic activity for the ketonization of AA. HA at high concentration (7 wt $\%$ ) inhibited the initial catalytic activity slightly more than FF at $350{ }^{\circ} \mathrm{C}$, likely due to the high reactivity of HA on CeZrOx giving various carbonyl compounds as shown in Figs. $5 \mathrm{~b}$ and 6. The catalytic activity loss by HA was overcome by proceeding the ketonization reaction at $450{ }^{\circ} \mathrm{C}$ (Fig. S4 in Electronic Supplementary Material), which is consistent with that reported by Jackson (2013) that at above $400{ }^{\circ} \mathrm{C}, 10 \mathrm{vol} \% \mathrm{HA}$ did not hinder the ketonization of a $16 \mathrm{vol} \%$ AA solution over $\mathrm{Fe}_{0.2} \mathrm{Ce}_{0.2} \mathrm{Al}_{0.6} \mathrm{O}_{\mathrm{x}}$. To further understand the behavior of FF and HA over the surface of catalyst, the ketonization of AA in the mixture as a function of TOS was carried out, and the results are shown in Figs. 7 and 8, respectively. When feeding the mixture of AA and FF (Fig. 7a), the initial conversion of AA was about $40 \%$ and decreased to below $5 \%$ within $4 \mathrm{~h}$ on steam. In comparison with the ketonization reaction of pure AA (20 wt $\%$ solution) (conversion $=100 \%$ and acetone yield $=46 \%$ ), the presence of FF appears to significantly inhibit the ketonization reaction. However, FF does not appear to be significantly affected from AA, because the conversion of FF was about $20 \%$ (Fig. 7b), which is similar to the conversion of FF solution alone (Fig. 5a). After the reaction, bright brown products were found, having accumulated on the inner-wall of the quartz reactor between the furnace and the condenser. The brown products recovered using acetone mainly consisted of furfuralacetone $\left(\mathrm{C}_{8} \mathrm{H}_{8} \mathrm{O}_{2}\right)$ including some carbonyl components, based on the results of the GC/MS analysis. In other words, the aldol condensation reaction $\left(\mathrm{C}_{5} \mathrm{H}_{4} \mathrm{O}_{2}+\mathrm{C}_{3} \mathrm{H}_{6} \mathrm{O} \rightarrow \mathrm{C}_{8} \mathrm{H}_{8} \mathrm{O}_{2}+\mathrm{H}_{2} \mathrm{O}\right)$ between unreacted $\mathrm{FF}$ and produced acetone occurred during the ketonization of $\mathrm{AA}$ over $\mathrm{CeZrOx}$ at $350{ }^{\circ} \mathrm{C}$. Furfuralacetone is an important reaction product in the present catalytic reaction condition in terms of reduction of acidity and formation of larger carbon chains. When removing FF from the feed, the conversion of AA and acetone yield was restored to about $80 \%$ and above $30 \%$, respectively. This means that the FF induces reversible poisoning on the surface of the catalyst by merely blocking active sites. The complete recovery in the conversion and yield was not achieved, likely due to thermal coke, derived from FF, on the surface of the catalyst (Table 4). The co-presence of HA (7\%) in the AA solution showed different behaviors from the case of the FF mixed solution (Fig. 8a). The conversion of AA and acetone yield was about $20 \%$ and $10 \%$, respectively, with about $40 \%$ HA conversion. When comparing with the results of ketonization using each solution (AA or HA), the conversions were one-tenth and a half of each conversion, respectively. This indicates that the co-existence of AA and HA significantly influences their counterpart reactions: 


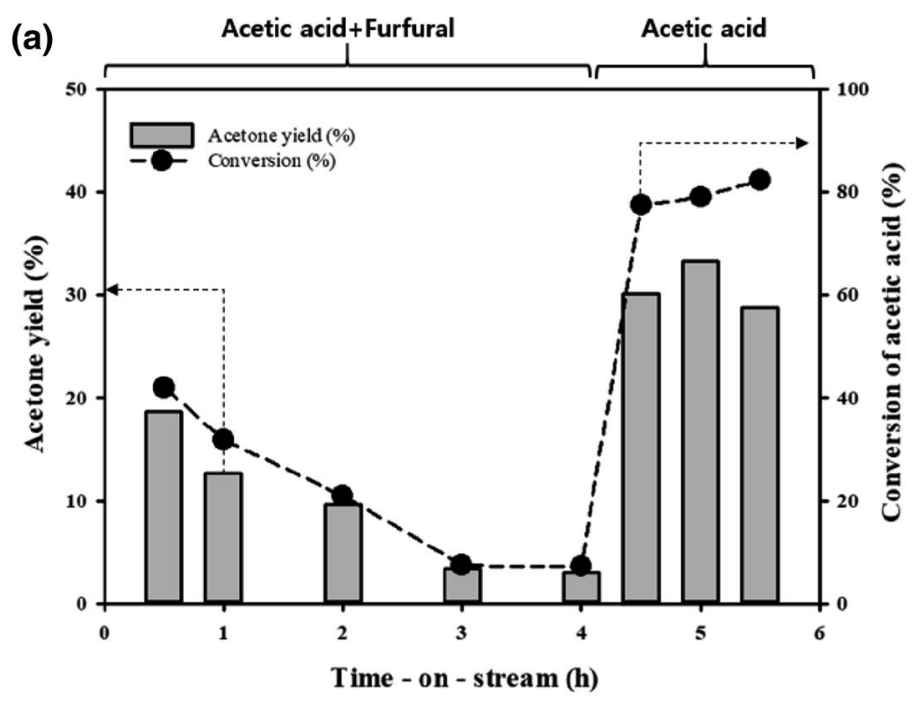

(b)

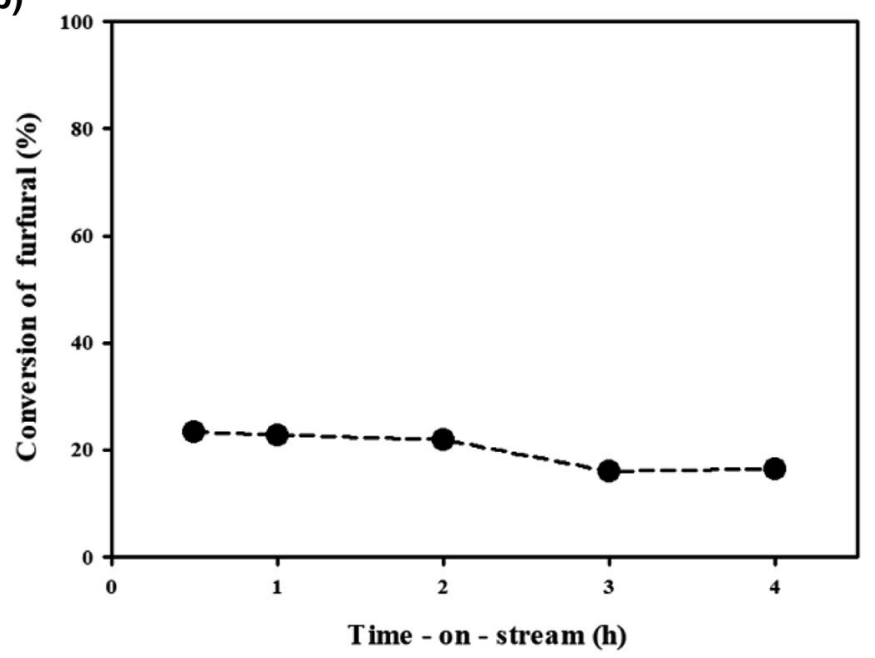

Fig. 7 Results of ketonization of AA in the mixture (20\% AA+7\% FF in water) over $\mathrm{CeZrOx}$ at $\mathrm{WHSV}=3 \mathrm{~h}^{-1}$ (based on AA) and $350{ }^{\circ} \mathrm{C}$ : a conversion of AA and acetone yield and $\mathbf{b}$ conversion of FF

ketonization of AA and complex reactions of HA for forming other carbonyl compounds. These results contrast with those of Hakim et al. (2013) who found that the presence of HA (5 wt\%) did not influence the ketonization activity (20 wt \% of AA) and both reactants (AA and HA) achieved more than $99 \%$ conversion at $350{ }^{\circ} \mathrm{C}$. The conversion of AA was not dramatically recovered as soon as HA was removed from the mixed solution, but appeared to be slowly restored. However, the conversion still reached 50\% after removing HA from the mixed solution $(2 \mathrm{~h})$. This indicates that 


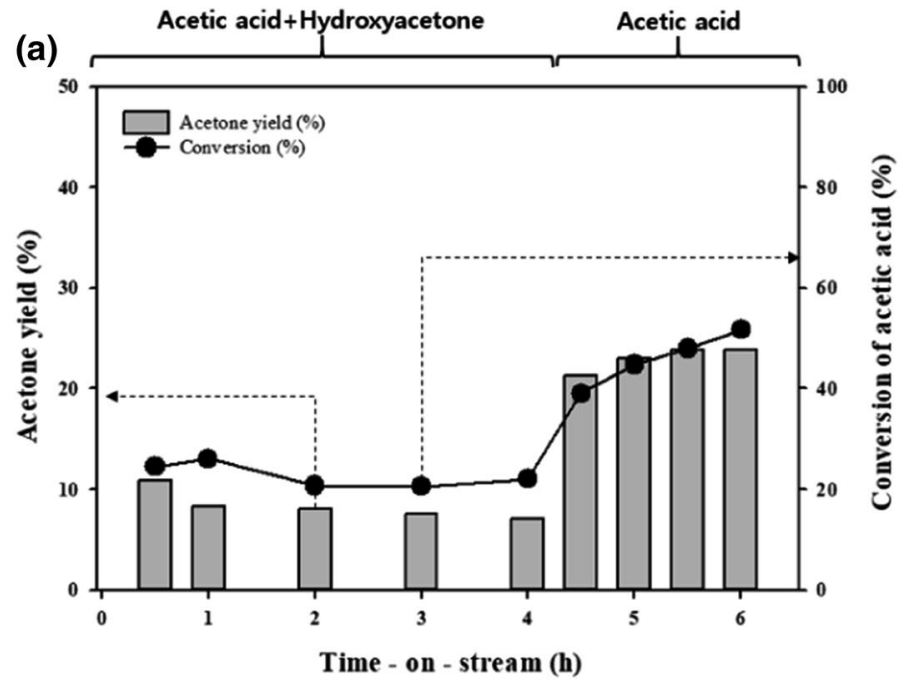

(b)

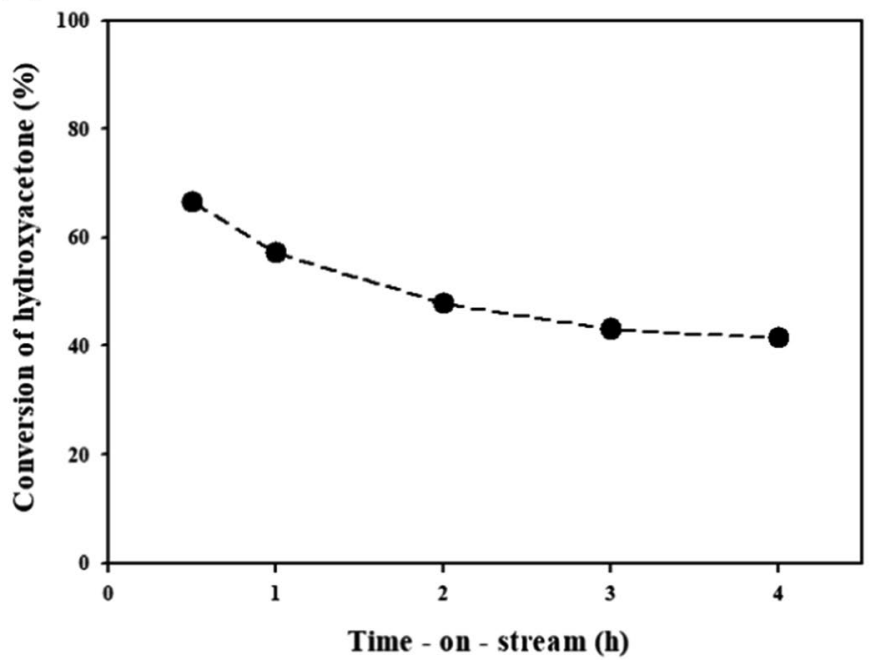

Fig. 8 Results of ketonization of AA in the mixture (20\% AA+7\% HA in water) over $\mathrm{CeZrOx}$ at WHSV $=3 \mathrm{~h}^{-1}$ (based on AA) and $350{ }^{\circ} \mathrm{C}$ : a conversion of AA and acetone yield and $\mathbf{b}$ conversion of HA

Table 4 Comparison of coke deposited on the CeZrOx catalyst after ketonization reaction (6 $\mathrm{h}$ TOS) using the different mixed solutions at 350 ${ }^{\circ} \mathrm{C}$ at $\mathrm{WHSV}=3 \mathrm{~h}^{-1}$ (based on AA)

\begin{tabular}{llll}
\hline$\% \mathrm{~g}_{\text {coke }} / \mathrm{g}_{\text {catalyst }}$ & $\begin{array}{l}20 \mathrm{wt} \% \\
\mathrm{AA}+7 \mathrm{wt} \%\end{array}$ & $\begin{array}{l}20 \mathrm{wt} \% \\
\mathrm{AA}+7 \mathrm{wt} \%\end{array}$ & $\begin{array}{l}20 \mathrm{wt} \% \mathrm{AA}+7 \\
\mathrm{wt} \% \mathrm{FF}+7 \mathrm{wt} \% \\
\mathrm{HA}\end{array}$ \\
\hline Thermal coke & 1.46 & 0.53 & 0.5 \\
Catalytic coke & 0.00 & 0.03 & 0.09 \\
Total coke & 1.46 & 0.56 & 0.59 \\
\hline
\end{tabular}


various carbonyl compounds derived from HA, unlike FF, adsorb strongly on the surface of the catalyst (severe poisoning).

The results of ketonization of $\mathrm{AA}$ in the mixed solution $(20 \% \mathrm{AA}+7 \% \mathrm{FF}+7 \%$ $\mathrm{HA}$ in water) at $350{ }^{\circ} \mathrm{C}$ are shown in Fig. 9. As expected, the conversion of AA and acetone yield was, unfortunately, about $10 \%$ and below $10 \%$, respectively, due to the co-existing reactants. HA was the most reactive on $\mathrm{CeZrOx}$ among the reactants early in the reaction (initial conversion $=46 \%$ ), but its conversion dramatically dropped to about $10 \%$ on stream. The significant reduction in the catalytic activity is likely due to the competitive adsorption of AA, FF and carbonyl components formed from HA on the active sites, as demonstrated before. As shown in Table 4, the amount of catalytic coke deposited in the spent catalysts increased as the number of reactants in the solution increased, but thermal coke decreased even if FF was co-fed. Instead, the larger amount of humin-like products were adhered on the inner surface of the tubular reactor, when using the AA + FF + HA mixed solution rather than the AA+FF solution. As shown in Fig. S4, the inhibition of the ketonization of AA by adding HA and FF could be overcome by proceeding the reaction at 450 ${ }^{\circ} \mathrm{C}$. Long-term operation ( 5 cycles) for ketonization of AA in the mixture, therefore, was conducted at $450{ }^{\circ} \mathrm{C}$, and the spent catalyst was in situ regenerated periodically using air at $450{ }^{\circ} \mathrm{C}$ for $2 \mathrm{~h}$. The conversions of reactants and acetone yield as a function of TOS are shown in Fig. 10, giving acetone without any unreacted AA remaining on stream. Acetone yield (about 40\%) was reasonable considering the following: product loss during the sampling and coke formation originated from the high temperature operation, as mentioned earlier. The conversions of HA and FF followed similar trends to those in Fig. S3. Severe thermal coke formation was, however, unavoidable on top of the catalyst bed during the long-term operation using the mixed solution.

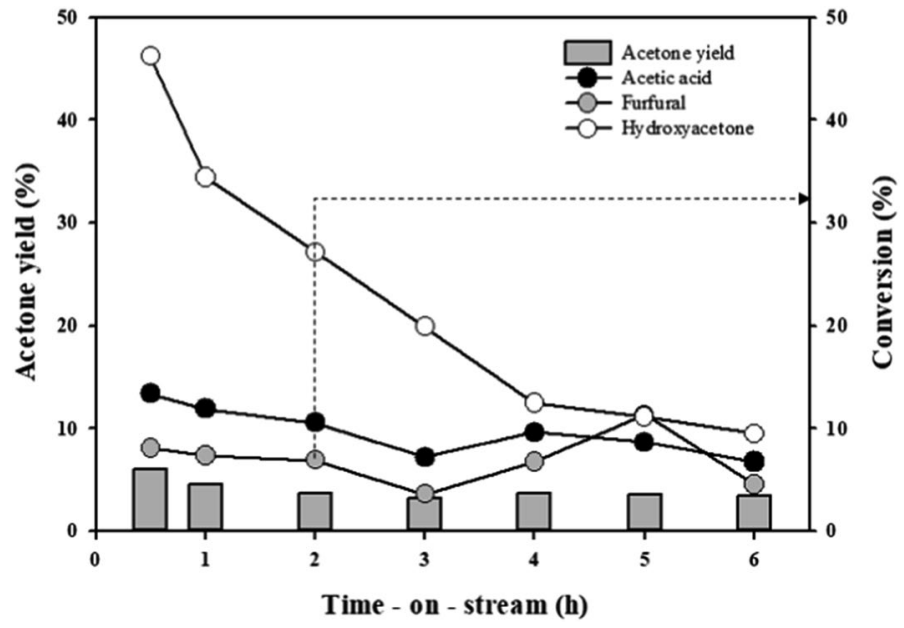

Fig. 9 Results of ketonization of AA in the mixture (20\% AA + 7\% FF+7\% HA in water) over CeZrOx at WHSV $=3 \mathrm{~h}^{-1}$ (based on AA) and $350{ }^{\circ} \mathrm{C}$ 


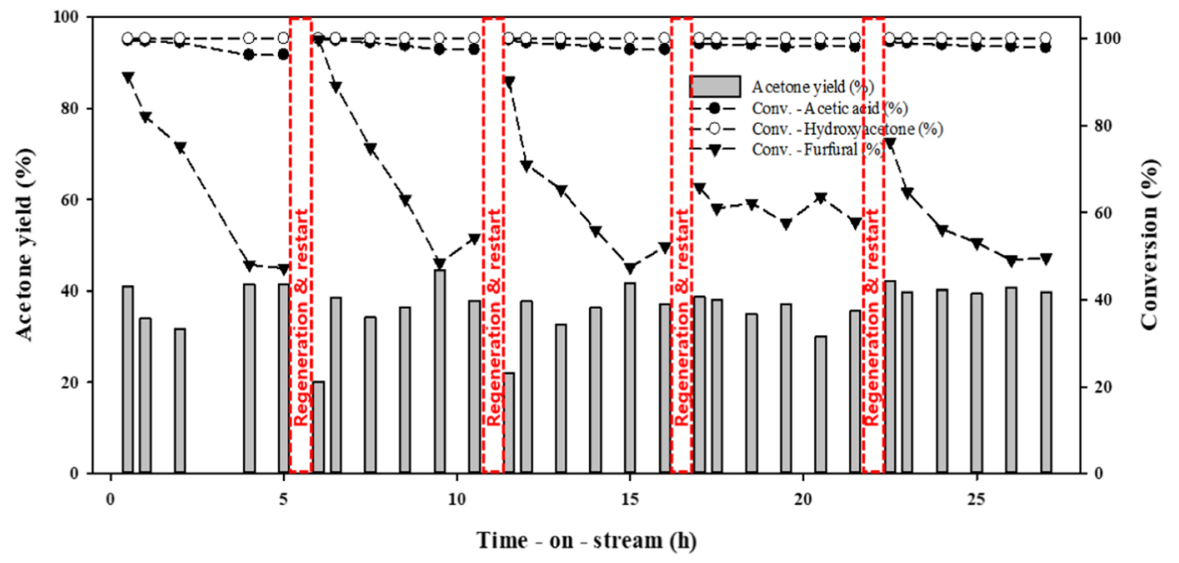

Fig. 10 Results of long-term operation using the mixture (20\% AA+7\% FF+7\% $\mathrm{HA}$ in water) over CeZrOx at WHSV $=3 \mathrm{~h}^{-1}$ (based on AA) and $450{ }^{\circ} \mathrm{C}$ (catalyst regeneration using air at $450{ }^{\circ} \mathrm{C}$ for $2 \mathrm{~h}$ )

To produce sustainable bio-fuel and bio-chemicals from the pyrolysis oil of woods, the first important reaction is the ketonization of carboxylic acid, which not only reduces a large amount of carboxylic acid but also converts it to less reactive intermediates with larger carbon numbers. However, based on the present results, just a few co-feed reactants significantly influence the catalytic activity for ketonization of carboxylic acids. In practice, abundant carbonyl components are present in the aqueous-phase bio-oil and different chemical reactions including self-/crossketonization, aldol condensation and carbonyl-forming reactions are involved under the reaction conditions. There are limitations to obtain enough information due to the heterogeneity of the present species and a merely qualitative analysis. If a comprehensive qualitative and quantitative analysis is established, more strategic and systematic studies would be possible to gain more information on these effects.

\section{Conclusion}

Ketonization has been investigated in mixed model solutions of different carboxylic acids, FF and HA, to understand the influence of co-feed reactants on the performance of ketonization of AA over the selected CeZrOx catalyst, and the experimental observations are as follows.

(1) In the case of self-ketonization of different carboxylic acids, relatively higher reaction temperature is needed for complete conversion of carboxylic acids with the increase in carbon number in the molecules.

(2) When FF (7\%) was co-fed with AA solution, FF largely inhibited the catalytic activity within $4 \mathrm{~h}$ on stream, but the blocking of active sites by FF was immediately removed by removing FF from the feed. However, the complete recovery 
in the conversion and yield was not achieved, likely due to thermal coke $(1.46 \%$ $\left.\mathrm{g}_{\text {coke }} / \mathrm{g}_{\text {catalyst }}\right)$, derived from FF, on the surface of the catalyst. Aldol condensation also occurred during ketonization with the mixture of $\mathrm{FF}$ and $\mathrm{AA}$ over $\mathrm{CeZrOx}$ at $350{ }^{\circ} \mathrm{C}$, producing furfuralacetone $\left(\mathrm{C}_{8} \mathrm{H}_{8} \mathrm{O}_{2}\right)$ adduct.

(3) In the case of co-feeding $\mathrm{HA}(7 \%)$ with AA solution, both reactants influenced each other, resulting in very low conversions: one-tenth and a half of each conversion of pure solution at $350{ }^{\circ} \mathrm{C}$. Reactive $\mathrm{HA}$ over $\mathrm{CeZrOx}$ produced various carbonyl compounds with less oxygen and some catalytic coke $\left(0.03 \% \mathrm{~g}_{\text {coke }} /\right.$ $\mathrm{g}_{\text {catalys }}$ ), unlike the FF mixture. The catalytic activity was slowly restored, but the conversion still reached 50\%, after removing HA from the mixture.

(4) For the mixed solution (20\% AA $+7 \% \mathrm{FF}+7 \% \mathrm{HA}$ in water), HA was the most reactive on $\mathrm{CeZrOx}$ among the co-feed reactants early in the reaction at 350 ${ }^{\circ} \mathrm{C}$, but its conversion dramatically dropped to about $10 \%$ on stream, due to the inhibition of co-existing carbonyl components. The inhibition of the ketonization of AA by adding HA and FF could be overcome by proceeding the reaction at $450{ }^{\circ} \mathrm{C}$. Severe thermal coke formation was, however, unavoidable on top of the catalyst bed during long-term operation.

Supplementary Information The online version contains supplementary material available at https://doi. org/10.1007/s00226-021-01333-2.

Acknowledgements This work was supported by the National Research Foundation of Korea(NRF) grant funded by the Korea government(MSIT) (No. NRF2020M1A2A207980211)

Authors' contributions IC was involved in methodology, experiment, analysis, investigation, visualization, and writing - original draft. HL contributed to experiment, formal analysis, investigation and visualization. KH was involved in conceptualization, supervision, project administration and writing-review and editing.

Funding The National Research Foundation of Korea grant funded by the Korea government.

Data availability Datasets used during this study are openly available, and the data citation in the main article has the full URL.

\section{Declarations}

Conflicts of interest The authors declare that they have no known competing financial interests or personal relationships that could have appeared to influence the work reported in this paper.

Open Access This article is licensed under a Creative Commons Attribution 4.0 International License, which permits use, sharing, adaptation, distribution and reproduction in any medium or format, as long as you give appropriate credit to the original author(s) and the source, provide a link to the Creative Commons licence, and indicate if changes were made. The images or other third party material in this article are included in the article's Creative Commons licence, unless indicated otherwise in a credit line to the material. If material is not included in the article's Creative Commons licence and your intended use is not permitted by statutory regulation or exceeds the permitted use, you will need to obtain permission directly from the copyright holder. To view a copy of this licence, visit http://creativecommons.org/licen ses/by/4.0/. 


\section{References}

Basahel SN, Ali TT, Mokhtar MM, Narasimharao K (2015) Influence of crystal structure of nanosized $\mathrm{ZrO}_{2}$ on photocatalytic degradation of methyl orange. Nanoscale Res Lett 10:73-85. https://doi. org/10.1186/s11671-015-0780-z

Boekaerts B, Sels BF (2021) Catalytic advancements in carboxylic acid ketonization and its perspectives on biomass valorisation. Appl Catal b: Environ 283:119607-119643. https://doi.org/10. 1016/j.apcatb.2020.119607

Boscagli C, Raffelt K, Zevaco TA, Olbrich W, Otto TN, Sauer J, Grunwaldt JD (2015) Mild hydrotreatment of the light fraction of fast-pyrolysis oil produced from straw over nickel based catalysts. Biomass Bioenerg 83:525-538. https://doi.org/10.1016/j.biombioe.2015.11.003

Dubnová L, Smoláková L, Kikhtyanin O, Kocík J, Kubička D, Zvolská M, Pouzar M, Čapek L (2020) The role of $\mathrm{ZnO}$ in the catalytic behaviour of $\mathrm{Zn}-\mathrm{Al}$ mixed oxides in aldol condensation of furfural with acetone. Catal. Today 379:181-191. https://doi.org/10.1016/j.cattod.2020.09.01

Hakim S, Shanks BH, Dumesic JA (2013) Catalytic upgrading of the light fraction of a simulated bio-oil over CeZrOx catalyst. Appl Catal b: Environ 142-143:368-376. https://doi.org/10.1016/j. apcatb.2013.05.021

Han Y, Gholizadeh M, Tran CC, Kaliaguine S, Li CZ, Olarte M, Garcia-Perez M (2019) Hydrotreatment of pyrolysis bio-oil: a review. Fuel Process Technol 195:106140-110668. https://doi.org/ 10.1016/j.fuproc.2019.106140

Han D, Yin W, Arslan A, Liu T, Zheng Y, Xia S (2020) Stabilization of fast pyrolysis liquids from biomass by mild catalytic hydrotreatment: model compound study. Catalysts 10:402-421. https:// doi.org/10.3390/catal10040402

Hwang KR, Park JS, Ihm SK (2011) Si-modified $\mathrm{Pt} / \mathrm{CeO}_{2}$ catalyst for a single-stage water-gas shift reaction. Int J Hydrog Energy 36:9685-9693. https://doi.org/10.1016/j.ijhydene.2011.05.065

Ignatchenko AV, Kozliak E (2012) Distinguishing enolic and carbonyl components in the mechanism of carboxylic acid ketonization on monoclinic zirconia. ACS Catal 2:1555-1562. https://doi.org/ $10.1021 / \operatorname{cs} 3002989$

Jackson MA (2013) Ketonization of model pyrolysis bio-oil solutions in a plug-flow reactor over a mixed oxide of Fe, Ce, and Al. Energy Fuels 27:3936-3943. https://doi.org/10.1021/ef400789z

Kulik T, Palianytsia B, Larsson M (2020) Catalytic pyrolysis of aliphatic carboxylic acids into symmetric ketones over ceria-based catalysts: kinetics, isotope effect and mechanism. Catalysts 10:179-199. https://doi.org/10.3390/catal10020179

Kumar R, Enjamuri N, Shah S, Al-Fatesh AS, Bravo-Suárez JJ, Chowdhury B (2018) Ketonization of oxygenated hydrocarbons on metal oxide based catalysts. Catal Today 302:16-49. https://doi. org/10.1016/j.cattod.2017.09.044

Lemonidou A, Vagia EC, Lercher J (2013) Acetic acid reforming over Rh supported on $\mathrm{La}_{2} \mathrm{O}_{3} / \mathrm{CeO}_{2}$ $\mathrm{ZrO}_{2}$ : catalytic performance and reaction pathway analysis. ACS Catal 3:1919-1928. https://doi. org/10.1021/cs4003063

Lyu G, Wu S, Znang H (2015) Estimation and comparison of bio-oil components from different pyrolysis conditions. Front Energy Res. https://doi.org/10.3389/fenrg.2015.00028

Mansur D, Yoshikawa T, Norinaga K, Hayashi J, Tago T, Masuda T (2013) Production of ketones from pyroligneous acid of woody biomass pyrolysis over an iron-oxide catalyst. Fuel 103:130134. https://doi.org/10.1016/j.fuel.2011.04.003

Park YK, Jung JS, Jae JH, Hong SB, Watanabe A, Kim YM (2019) Catalytic fast pyrolysis of wood plastic composite over microporous zeolites. Chem Eng J 377:119742-119750. https://doi.org/ 10.1016/j.cej.2018.08.128

Pham TN, Shi D, Sooknoi T, Resasco DE (2012) Aqueous-phase ketonization of acetic acid over Ru/ $\mathrm{TiO}_{2}$ /carbon catalysts. J Catal 295:169-178. https://doi.org/10.1016/j.jcat.2012.08.012

Raguindin RQ, Gebresillase MN, Han SJ, Seo JG (2020) Hydroxyalkylation/alkylation of 2-methylfuran and furfural over niobic acid catalysts for the synthesis of high carbon transport fuel precursors. Sustain Energ Fuels 4:3018-3028. https://doi.org/10.1039/D0SE00267D

Rezaei PS, Shafaghat H, Daud WMAW (2015) Suppression of coke formation and enhancement of aromatic hydrocarbon production in catalytic fast pyrolysis of cellulose over different zeolites: effects of pore structure and acidity. RSC Adv. https://doi.org/10.1039/C5RA11332F 
Shao S, Dong W, Li X, Zhang H, Xiao R, Cai Y (2020) Solvent-free synthesis of jet fuel by aldol condensation and hydroprocessing of cyclopentanone as biomass-derivates. J Clean Prod 250:119459-119469. https://doi.org/10.1016/j.jclepro.2019.119459

Snell RW, Shanks BH (2013) Ceria calcination temperature influence on acetic acid ketonization: mechanistic insights. Appl Catal a: Gen 451:86-93. https://doi.org/10.1016/j.apcata.2012.08.043

Su M, Li W, Zhang T, Xin H, Li S, Fan W, Ma LL (2017) Production of liquid fuel intermediates from furfural via aldol condensation over lewis acid zeolite catalysts. Catal Sci Technol 7:3555-3561. https://doi.org/10.1039/C7CY01028A

Wang H, Male J, Wang Y (2013) Recent advances in hydrotreating of pyrolysis bio-oil and its oxygencontaining model compounds. ACS Catal 3:1047-1070. https://doi.org/10.1021/cs400069z

Westerhof RJM, Brilman DWF, Garcia-Perez M, Wang Z, Oudenhoven SRG, Kersten SRA (2012) Stepwise fast pyrolysis of pine wood. Energy Fuels 26:7263-7273. https://doi.org/10.1021/ef301 $319 \mathrm{t}$

Xiong Z, Chen Y, Azis MM et al (2020) Roles of furfural during the thermal treatment of bio-oil at low temperatures. J Energy Chem 50:85-95. https://doi.org/10.1016/j.jechem.2020.03.015

Yu J, Biller P, Mamahkel A, Klemmer M, Becker J, Glasius M, Iversen BB (2017) Catalytic hydrotreatment of bio-crude produced from the hydrothermal liquefaction of aspen wood: a catalyst screening and parameter optimization study. Sustain Energ Fuels 1:832-841. https://doi.org/10. 1039/C7SE00090A

Publisher's Note Springer Nature remains neutral with regard to jurisdictional claims in published maps and institutional affiliations. 